\title{
O ÁUDIO INVISÍVEL: UMA ANÁLISE AO PODCAST DOS JORNAIS PORTUGUESES
}

\author{
Ana Isabel Reis
}

\begin{abstract}
Resumo
Desde os primórdios da internet que o som nos conteúdos jornalísticos ocupa um lugar secundário ou acessório. O subaproveitamento do som no ciberjornalismo tem sido reconhecido por académicos e profissionais, e só mais recentemente os jornais portugueses parecem ter-se apercebido das potencialidades do som e começado a produzir conteúdos sonoros exclusivos que distribuem em podcast. Este estudo incide em três jornais portugueses de informação geral (Público, Expresso e Observador), os únicos em que foram encontrados podcasts atualizados. Nesse sentido, serão analisados os produtos sonoros disponibilizados nos respetivos sites dos três jornais, nas suas contas no Soundcloud e no iTunes. O objetivo é caracterizar o áudio em podcast destas publicações para perceber como um jornal em ambiente digital desenvolve produtos sonoros e se contém elementos distintivos que possam revelar uma identidade própria. Perante as possibilidades do aproveitamento do áudio e do podcast uma das conclusões deste estudo é a de que depois de um momento de tímido investimento nos conteúdos áudio, de avanços e recuos na última década, os jornais começaram finalmente, a apostar no som embora ainda de forma exploratória e muito próxima do produto radiofónico.
\end{abstract}

\section{Palavras-chave}

Áudio; jornais; jornalismo; podcast; rádio

\begin{abstract}
Since the dawn of the internet, sound in journalistic content has assumed a secondary, ancillary role. Under-use of sound within the context of cyber-journalism has been recognised by academics and professionals. It appears that Portuguese newspapers have only recently realised the full potential of sound, as they have begun to produce exclusive sound content, distributed via podcasts. This study focuses on three Portuguese generalist newspapers (Público, Expresso and Observador), which are the only newspapers where updated podcasts were found. The text will analyse the sound products available in the respective websites of these three newspapers, and in their Soundcloud and iTunes accounts. It aims to classify the audio contained in the podcasts of these publications, in order to understand how a newspaper develops sound products in a digital environment and whether they contain distinctive elements that may reveal a distinct identity. Given the possibilities of using audio and podcasts, one of the conclusions of this study is that after an initial period of rather timid investment in audio content, and following various advances and setbacks over the last decade, Portuguese newspapers have finally begun to make a firm commitment to sound production, albeit on an exploratory basis and in a form that is very similar to radio.
\end{abstract}

\section{KEYWORDS}

Audio; journalism; newspapers; podcast; radio 


\section{OS MÉdIA E O PODCAST}

Desde o início que o papel do som no ciberjornalismo tem sido relegado para um plano secundário. Em muitos cibermeios é mesmo inexistente, noutros surge como um repetidor de texto, noutros ainda é um complemento inserido em trabalhos multimédia. O subaproveitamento das potencialidades da internet, e especificamente do áudio, revela um progressivo desinteresse por um meio rico em possibilidades expressivas multimédia (Zamith, 2008) que não se tem alterado nos últimos 10 anos (Zamith, 2017). A isto, junta-se a fraca perceção sobre a função dos recursos sonoros na mensagem jornalística por parte de quem a produz, sejam as empresas sejam os próprios jornalistas. A importância do som no jornalismo é, sobretudo, enfatizada pelos autores que estudam a rádio, os meios sonoros e a linguagem radiofónica.

Aos jornalistas é hoje exigida uma perceção diferente sobre a forma de contar histórias e "montar" as reportagens no ambiente digital. É requerida uma formação multidisciplinar porque o jornalista é agora um jornalista multimédia interativo capaz de trabalhar com técnicas variadas, e que terá de saber escrever para ser lido, ouvido e visto (Garrand, 2006). Os jornais já não se limitam a reproduzir textos nos seus sites, enriquecem as peças jornalísticas com outras linguagens contribuindo para a construção de novas narrativas jornalísticas. Os recursos visuais, como o vídeo, são, manifestamente, os elementos mais usados e invocados pelos responsáveis dos média quando destacam as novidades ou o que consideram mais relevante nos sites. Raramente são referidos os conteúdos áudio. O som não conquistou ainda um papel que permita afirmar-se nos conteúdos jornalísticos online. Esta realidade tem perdurado no tempo e tem raízes na evolução dos média na web, inicialmente mais dominada pela palavra escrita e com condicionalismos técnicos que limitavam o uso do áudio. Só em 1995 foi possível integrar o áudio e o streaming nos sites com a introdução do Real Audio Player e a digitalização do som em ficheiros mp3. Mesmo assim, as limitações técnicas revelaram-se um entrave à utilização do som nos sites dos órgãos de comunicação social, incluindo os das rádios.

Em 2001 surge o primeiro audioblogue que Gallego (2010) considera o percursor do podcast. O boom dá-se depois de 2004 aquando da publicação de um artigo no The Guardian sobre o sucesso da descarga de ficheiros áudio da internet. O que chamar-Ihe?, questiona-se o jornalista: "Audioblogging? Podcasting? GuerillaMedia?" (Ben Hammersley, 2004). Podcast é a resposta: conteúdos áudio criados em formato mp3 que os usuários podem subscrever e receber em casa, descarregar e ouvir em diversos dispositivos (Berry, 2006). E que podem ser produzidos por editores tradicionais como rádio, editoras, jornalistas e instituições educacionais (escolas, centros de formação profissional), bem como conteúdo criado por produtores de rádio independentes, artistas e rádio amadores (Bonini, 2015).

Richard Berry não olha o podcast apenas como uma nova plataforma de distribuição. É um novo medium, escreve, porque não é apenas o resultado da junção do áudio, da internet e dos dispositivos portáteis; é uma tecnologia disruptiva que já obrigou as rádios a reconsiderarem as suas perceções sobre as audiências, consumo, produção e distribuição (Berry, 2006, p. 357). Ou seja, não é apenas mais uma tecnologia ao dispor 
da rádio, é um meio que ainda está a desenvolver uma identidade própria não necessariamente dependente ou ligada à rádio, embora esse ainda seja o seu ponto de referência. Escreve Richard Berry: "o podcasting parece-se com a rádio" (mas) "soa diferente da rádio". Avaliar o podcast segundo os parâmetros radiofónicos pode condicionar a perceção sobre o que é o podcast e o que o distingue (Berry, 2016). Os dois estão intimamente ligados, partilham tecnologias, técnicas e conteúdos, coexistem, mas trilham caminhos divergentes que se intersetam. Por isso, conclui Berry, "o podcast pode (mas não tem que) soar diferente da rádio". E aponta algumas características que definem a rádio que estão sobretudo relacionadas com a temporalidade, mas que estão ausentes do podcasting: periodicidade regular, emissão/publicação em horários pré-determinados, duração fixa, direto, fluxo contínuo - mesmo que tenham outras similitudes, essencialmente as relacionadas com os conteúdos e a estética sonora.

Nos média, foram as rádios as primeiras a disponibilizar podcast dos seus programas emitidos por via hertziana, os jornais seguiram-lhes os passos. É uma forma de ampliarem as suas matérias e os jornais convertem-se em geradores de conteúdos áudio porque é barato e simples, é um novo campo em expansão e uma nova forma de explorar marcas históricas com grande credibilidade (Gallego, 2010) - uma estratégia que pode ser facilitada pelo atual panorama da propriedade dos média dominado pela concentração dos meios em que os grandes grupos detêm rádios, jornais, televisões e portais na internet. As políticas de sinergias de grupo ou de implementação de redações convergentes são igualmente contributos para que haja uma convergência nos conteúdos. Isso mesmo concluem Correyero Ruiz y Baladrón Pazos (2007, p. 167) para quem o podcast é um "catalisador da futura convergência mediática". Os dois autores analisaram o podcast nos média espanhóis e identificaram quatro funções mais comuns para o uso do som: divulgação da primeira página, destaques do dia ou exclusivos; difusão de documentos sonoros como entrevistas, tertúlias e reportagens; criação de novos conteúdos diferentes do meio-mãe; e o podcast como ferramenta para estimular a participação dos leitores (Correyero Ruiz \& Baladrón Pazos, 2007, pp. 159-161).

O Daily Telegraph no Reino Unido foi o primeiro jornal a lançar um podcast diário em 2005 (Bonini, 2015). Em março de 2006 o jornal britânico The Guardian lançou 23 canais de podcast especializados em temáticas da atualidade. Ignacio Gallego, no livro, Podcasting. Nuevos modelos de distribución para los contenidos sonoros (2010), dedica-lhe parte de um capítulo e transcreve as perceções do responsável de Audio\&Podcast Matt Wells sobre esta mais-valia: mais proximidade e interação com os leitores, afirmação da marca do jornal e uma nova forma de publicidade já que os canais eram patrocinados. Ao longo da década os jornais acabaram por desinvestir neste produto por manifesta falta de retorno financeiro e de descargas. Um panorama que muda em 2012 quando se inicia, como defende Bonini a "segunda era do podcasting" impulsionada pelo crowdfunding, pelo uso generalizado dos smartphones e pela criatividade de uma nova geração de produtores. O podcast tornou-se mais popular e mais atraente para o mercado dos média tradicionais, (Bonini, 2015, p. 25) sobretudo por razões económicas: "principalmente dinheiro" é a palavra-chave na renovação do podcasting. Ao fim de uma década, defende o autor, o podcast passou do do-it-yourself 
amador para um meio de comunicação comercial (Bonini, 2015, p. 27). Embora se reconheça que este é um nicho de mercado, a tendência internacional é de crescimento, e são cada vez mais as publicações que estão a capitalizar esta tendência produzindo e distribuindo podcast (Digital News Fact Sheet, 2017; Podcasting: Fact Sheet, 2016).

\section{O CASO PORTUGUÂS}

Olhando para a história dos cibermeios nacionais, registamos o facto de alguns títulos terem sido pioneiros na inclusão do som nos seus conteúdos ao lançarem "programas" que podiam ser descarregados dos sites para serem ouvidos mais tarde, os podcasts.

A década de 90 marcou a estreia dos média portugueses na internet. Uma entrada tímida e uma presença discreta dominada pelo modelo shovelware em que jornais, rádios e televisões reproduzem nos sites os conteúdos produzidos para os meios tradicionais (Bastos, 2015). Estávamos na fase da implementação (1995-1998), segundo Hélder Bastos (2015), a que se seguiram as fases da expansão ou boom (1999-2000) com a aposta no digital e o aparecimento de publicações exclusivamente online e, finalmente, a fase da contração (2001-2015), assistindo-se ao desinvestimento no setor agravado pela crise de 2009 que levou ao encerramento de vários meios no online, embora se tenham registado alguns investimentos contra corrente. Segundo Bastos, "a evolução no campo do ciberjornalismo viria a revelar-se lenta e pontuada por diversas frustrações" (Bastos, 2006, p. 105). Diz o autor que a "dificuldade em encontrar modelos de negócio de sucesso levou a generalidade dos investidores a desinteressarem-se do ciberjornalismo", mas o “cenário 'altera-se ligeiramente' no segundo semestre de $2006 \mathrm{com}$ o aparecimento de alguns projetos inovadores (Bastos, 2015, p. 63), a par de tímidas apostas no multimédia (Zamith, 2008), nomeadamente no podcasting. A TSF é a primeira a lançar programas em podcast, uma estratégia seguida depois por outros média, designadamente jornais.

Em 2006 o Expresso foi o primeiro jornal português a apresentar os formatos áudio no site e com características inovadoras, como por exemplo, um programa de música próprio e exclusivo: o Íntima Fracção de Francisco Amaral, que tinha um longo percurso nas rádios portuguesas e que se transferiu para o site do semanário.

O ciberjornal Observador é criado em maio de 2014 e assume-se como um "nativo digital". O seu primeiro podcast é publicado no dia 13 de fevereiro de 2015, Dia Mundial da Rádio. São 22 segundos ouvidos no Soundcloud em que David Dinis, então diretor executivo, anuncia dois programas com distribuição em podcast. E, na verdade, é o único podcast do Observador. Nessa categoria não foram encontrados conteúdos exclusivamente sonoros, apenas aparecem programas vídeo classificados e anunciados como podcast, e que são distribuídos pelo iTunes ou RSS e recebidos pelos utilizadores apenas na sua versão áudio. Na sua essência não são podcasts, mas também não são videocast porque apesar de serem vídeo apenas podem ser recebidos via áudio.

O Público foi tendo algumas experiências áudio e inclui som em algumas peças jornalísticas, nomeadamente no $P_{3}$, ou em alguns especiais como aconteceu no caso recente do campeonato nacional de futebol em que articulou imagens com os sons dos golos. 
O podcast é incluído de forma regular em 2017 quando foram comemorados os 22 anos do Público online, data em que é apresentado o novo site com uma clara aposta no podcasting.

\section{Metodologia}

O objetivo deste estudo é o de caracterizar o áudio em podcast dos jornais portugueses de informação geral. Pretende-se ainda perceber como um jornal em ambiente digital desenvolve formatos áudio em podcast para o site, com distribuição no Soundcloud e iTunes, e se estes contêm elementos distintivos que possam revelar uma identidade própria. Foram excluídos desta análise os áudios de reportagens, notícias ou peças multimédia de outras secções ou editorias.

O conjunto de podcasts selecionados recai nas três únicas publicações online de informação geral que apresentam programas áudio no site com distribuição em podcast: Expresso, Público e Observador. Por essa razão, foram incluídos os programas em vídeo do Observador que são distribuídos em podcast através do iTunes. Embora não sejam programas áudio ou conteúdos exclusivamente sonoros chegam por essa via à audiência do ciberjornal que os procura posteriormente. Da amostra fazem parte, igualmente, programas que já não sejam atuais, mas que ainda estejam disponíveis no site na área reservada ao podcast. Assim, foram analisados todos os podcast acessíveis nos três sites, no Soundcloud ou no iTunes até 31 de outubro de 2017, num total de 19 produtos neste formato.

O semanário Expresso foi criado em 1973. É um jornal de referência, tem cerca de 91 mil exemplares de tiragem' e no Netscope $^{2}$ tem 9,4 milhões de visitas. O Expresso tem cinco podcasts. O jornal Público, por sua vez, é um diário de referência criado em 1990, tem cerca de 34 mil exemplares de tiragem ${ }^{3}$ e no Netscope ${ }^{4}$ tem 11 milhões de visitas. O Público tem oito podcasts. O Observador, nativo digital de referência nascido em 2014, não tem edição em papel (embora tenha anunciado a publicação impressa de um dos seus cadernos até ao final de 2017). Não faz parte do Netscope e quando anunciou a saída desse ranking, em março de 2016, tinha 7,9 milhões de visitas (Saímos do Netscope. E mostramos os nossos números, 2016). O Observador tem seis podcasts.

O número de podcasts por programas selecionados para esta análise é variável devido às suas características, número de publicações ou longevidade. Mesmo assim, para dar alguma coerência à representatividade de cada um, foram selecionados seis podcasts por ano de cada programa com exceção do $P_{24}$ por se tratar de um noticiário e cujas características serão detalhadas mais à frente. Do $P_{24}$ foram selecionados oito noticiários por mês, e no último mês da análise, porque houve uma alteração na periodicidade do conteúdo, foram analisadas as duas edições diárias.

\footnotetext{
' Dados da APCT relativos ao $4^{\circ}$ bimestre de 2017.

${ }^{2}$ Ranking Netscope de setembro de 2017.

3 Dados da APCT relativos ao $4^{\circ}$ bimestre de 2017.

${ }_{4}^{4}$ Ranking Netscope de setembro de 2017.
} 
Todos os podcasts estão acessíveis à audiência dos três jornais quer seja na versão gratuita quer seja na versão paga. A única exceção é o $P_{24}$ porque é um exemplo único nesta amostra e no panorama dos podcasts nos média portugueses uma vez que ofeed de notícias é personalizado, ou seja, o noticiário é "um conjunto de notícias em áudio, selecionadas a partir dos interesses de cada pessoa" (P24: Público lança noticiário personalizado em áudio, 2017), embora também inclua as escolhas do editor. Assim, dadas as características do $P_{24}$, o seu estudo está naturalmente limitado a um feed de notícias específico: o que o investigador recebe diariamente sem que possa aceder a todas as notícias que, eventualmente possam fazer parte do $P_{24}$ e sejam acedidas por outros utilizadores. Desta forma, a amostra recai apenas nas notícias áudio do $P_{24}$ de um único feed, o do investigador que, tentou diversificar ao máximo as editorias e interesses de forma a obter um leque o mais variado possível da temática noticiosa.

Para a caracterização dos podcasts dos três jornais foi elaborada uma grelha de análise que abarca aspetos formais, de conteúdo, de estrutura e estética radiofónica. Nos aspetos formais além da descrição apresentada por cada programa, registou-se a periodicidade, localização na homepage e no site, e os canais de distribuição. As restantes categorias têm como referência a classificação dos géneros radiofónicos de Herreros (1992) e Martínez-Costa y Unzueta (2005) e dos novos géneros na internet de Herreros (2008) e Prata (2009); os elementos da estética e da linguagem radiofónicas (Balsebre, 1994), estrutura e escrita radiofónicas (Prado,1985).

Em matéria de conteúdos distinguem-se os de Entretenimento (por área: música, ficção, etc.), Informação (por editoria: política, internacional, saúde, cultura, humor, etc.); Formação (para fins de ensino), Patrocinado ou Publicidade, e Propaganda. O humor foi incluído na categoria da Informação por duas razões: em primeiro lugar porque está intrinsecamente ligado aos temas da atualidade e em segundo lugar porque quer os sites quer o iTunes os classificam como Notícias. Ainda relativamente ao conteúdo, estrutura e estética radiofónica, foi registada a forma como é apresentado cada podcast.

\section{Os podcasts dos Jornais Portugueses Expresso, Público e ObSerVAdor}

Feito um levantamento dos sites dos jornais diários, semanários e revistas e dos ciberjornais de informação geral portugueses conclui-se que a grande maioria não tem conteúdos sonoros produzidos para a edição online. Em apenas três publicações foram encontrados formatos áudio exclusivos e apresentados como podcast e simultaneamente disponíveis no Soundcloud e no iTunes. Nos jornais o áudio surge de duas formas distintas: em programas distribuídos em podcast ou integrado em peças jornalísticas e trabalhos multimédia com uma função próxima daquilo que na gíria radiofónica se chama o RM, ou seja, excertos de declarações ou entrevistas: o som ou a voz dos protagonistas da notícia. Não foi encontrada uma categoria para o áudio ou para conteúdos sonoros, e a categoria Multimédia normalmente inclui apenas recursos visuais (vídeo, fotogaleria, infografia). Cabe ainda referir que da listagem de podcasts analisados nem todos estão ativos ou atualizados, casos do Expresso e do Observador que apresentam 
programas cujas últimas edições são datadas de há meses ou anos anteriores. Apenas os podcasts do Público correspondem aos que têm edições atuais.

No Expresso, os menus do site incluem uma secção para o podcast embora os conteúdos na página principal não destaquem edições recentemente publicadas. Há uma página podcast com o logótipo de cada programa que remete para a página de cada um que tem uma descrição sumária dos programas. A área Multimédia tem Áudio/Podcast na coluna lateral direita.

O Expresso tem acessíveis cinco podcasts de caráter jornalístico:

1. Comissão política - semanal, apresenta-se como o "podcast da secção de política do Expresso" em que jornalistas da redação analisam temas da atualidade "e do que não lhes sai da cabeça". O primeiro programa acessível data de setembro de 2017, inclui alguns episódios "extra" com temáticas específicas da atualidade.

2. A beleza das pequenas coisas - semanal, são "conversas pelo país" em que "as mais variadas personagens contam histórias maiores do que a vida. Ou tão simples como ela pode ser". Os entrevistados nem sempre são figuras públicas, e o programa recorre a sons, entrevistas anteriores, vox pop, depoimentos e às músicas preferidas do entrevistado. O primeiro programa acessível data de novembro de 2015, não se publicando em agosto.

3. $P B X$ - semanal, é uma conversa sobre a atualidade cultural feito em parceria com a rádio Radar, às vezes tem entrevistados. O primeiro programa acessível data de novembro de 2015 e não tem edições atualizadas nos três canais de distribuição desde julho de 2017.

4. Conselho de diretores - semanal, é o podcast de um programa da Rádio Renascença, feito em parceria com o Expresso, de análise política económica e social. O primeiro programa é de novembro de 2015 e o último de outubro de 2016.

5. $\quad F_{5}$ - quinzenal, apresenta-se como um programa com "histórias cheias de gente, contadas pelos repórteres do Expresso que não quiseram, ou não conseguiram, esquecê-las", ou seja, os repórteres do jornal são convidados a regressar a um trabalho que os marcou, sendo que são também ouvidos os protagonistas da reportagem dessa época. O $F_{5}$ tem apenas três programas publicados, o primeiro é de março de 2017.

No site do Público não é feita qualquer referência no menu à secção dos podcasts, a primeira surge a meio da homepage quando é destacado o último que foi publicado com um link para a página de todos os podcasts. Cada programa tem a sua própria página, com um logótipo próprio, uma descrição sumária de cada edição e acesso às últimas 10, e links para o Soundcloud e iTunes. A área Multimédia não inclui áudios.

O Público tem oito podcasts, sete de caráter jornalístico e um de humor:

1. Poder público - semanal, apresenta-se como "o outro lado da política com diferentes protagonistas, histórias que merecem ser contadas e decisões que mudam a vida das pessoas", o programa não tem uma estrutura rígida, inclui debate, entrevistas e reportagem. O primeiro programa data de março de 2017, mas nem todos estão acessíveis nos três canais de distribuição. De referir ainda que oito programas são dedicados exclusivamente às eleições autárquicas.

2. Reservado ao público - semanal, apresenta-se desta forma: "histórias e protagonistas dos bastidores do Público", e é efetivamente um programa de reportagem em que se faz o retrato do jornal e do seu dia a dia, das opções editoriais, e com as histórias que estão por trás das reportagens. O programa um é de março de 2017 , mas os seguintes só estão acessíveis a partir de maio. 
3. Inimigo público - semanal, identifica-se com uma única frase: "se não aconteceu, podia ter acontecido". Tem o mesmo nome de um caderno impresso do jornal, é feito, normalmente, a uma só voz embora possa conter curtas entrevistas. É um programa de humor sobre a atualidade. O programa começou em abril de 2017.

4. Jogo limpo - semanal, descreve-se como "o comentário e a análise aos lances que marcam o desenrolar da I Liga de futebol". Começou em agosto de 2017.

5. Do género - semanal, é uma reportagem com "conversas sobre igualdade no dia a dia". É o último podcast do Público, começou em outubro de 2017.

6. Com tempo e alma - quinzenal, é um debate em que "um jornalista e especialistas convidados pela Fundação Francisco Manuel dos Santos conversam sobre temas relevantes da sociedade". O primeiro programa acessível data de maio de 2017.

7. Planisférico - quinzenal, em que dois jornalistas do Público conversam e contam "histórias de campeonatos de futebol periféricos", podendo incluir algum som curto como mote da conversa e às vezes tem um link para a coluna do jornal que tem o mesmo nome. O primeiro programa é de abril de 2017.

8. $P_{24}$ - são notícias que podem ser escutadas isoladamente ou num fluxo contínuo apresentado como se fosse um noticiário. São "as 10 notícias do dia em menos de 10 minutos." O noticiário começou em abril de 2017, existe de segunda a sexta-feira com uma edição diária às 18 hoo, mas desde outubro que tem também uma edição ao final da manhã.

O Observador não tem áudios, mas vídeos que são intitulados de podcast. Esses programas não estão nos destaques da homepage, mas fazem parte do menu do topo que, quando se clica abre uma página intitulada Podcast em que aparecem os nomes dos programas com uma descrição sumária.

O Observador tem seis programas vídeo com distribuição podcast, cinco de conteúdo jornalístico e um de entretenimento:

1. Conversas à quinta - semanal, apresenta-se como um "programa de conversa semanal moderado com um painel fixo de comentadores. O primeiro programa acessível data de dezembro de 2014.

2. B.I.C.A. - sem periodicidade regular, é um espaço em que jornalistas do Observador discutem "todos os temas no tempo que demora a tomar um café". O primeiro programa é de abril de 2017.

3. Caça ao voto - diário, "uma caixa de comentários" às eleições autárquicas. Um formato idêntico ao que existiu nas presidenciais de 2016. Começou em setembro de 2017 e teve 11 episódios.

4. Comentários - semanal, é uma "análise das notícias do dia por parte dos jornalistas e comentadores do Observador", da atualidade nacional e internacional. O primeiro programa acessível é de março de 2017. Apesar de se assumir como semanal, não tem uma periodicidade regular ou fixa, surge quando há um tema forte da atualidade.

5. Entrevista - periodicidade irregular, é um programa de entrevistas a "personalidades que contam no momento em que precisam de ser escutadas". O primeiro programa acessível data de dezembro de 2014 .

6. Ao vivo - mensal, é um programa de entretenimento, que como o próprio nome indica regista "todos os momentos musicais ocorridos ao vivo na redação do Observador". O primeiro Ao vivo data de novembro de 2014 . 


\section{CARACTERIZAÇÃo doS PODCASTS NOS JORNAIS PORTUGUESES}

Ao longo do período em análise raramente os produtos sonoros foram alvo de destaque na homepage dos três sites, e entende-se por destaque uma localização no primeiro ecrã quando se abre o site. Expresso e Observador têm uma secção no menu principal. Quanto ao Público, na última renovação do site foi criado um espaço na homepage para os programas áudio, embora numa localização secundária a meio ou no final da página. Anteriormente o leitor tinha de procurar os podcasts no motor de busca do site sem que houvesse indicação da sua existência.

Embora na homepage os podcasts não tenham um lugar de destaque, dois dos três jornais dão-lhes páginas próprias com o logótipo de cada programa. O Observador tem uma página única para todos. Na página dos podcasts o Expresso e o Público apresentam habitualmente uma fotografia ou ilustração para cada programa assim como um resumo sumário do conteúdo, identificação dos entrevistados e/ou dos autores. Na página dos podcasts, no caso do Observador, ou de cada programa no caso do Expresso e do Público, disponibilizam-se entre cinco e 10 últimas edições.

$\mathrm{Na}$ apresentação escrita conclui-se que a maioria dos programas tem uma periodicidade regular, semanal, e que as publicações são feitas num dia fixo da semana. Mas na prática nem sempre se cumpre, como se falará mais à frente. O Público tem publicações agendadas para todos os dias úteis, com maior concentração à quinta e sexta-feira. $O$ Expresso tem dois com periodicidade irregular e com um fluxo intermitente (Conselho de diretores e o F5), ou seja, nem sempre são publicados no mesmo dia da semana, o espaço temporal entre programas nem sempre é o mesmo e não há programas recentes.

Regra geral, os programas do Observador não têm uma periodicidade definida nem dia fixo para serem publicados. O Comentários, por exemplo, tanto tem publicações diárias como semanais. $O$ único que cumpre a publicação regular num dia fixo da semana é o Conversas à quinta.

Ao contrário da rádio o tempo médio dos podcasts é variável de edição para edição. $O$ facto de a periodicidade e a duração destes programas serem variáveis afasta o podcast do programa radiofónico sujeito a uma duração estável, fixa, e integrada no fluxo contínuo da grelha de programação. $\mathrm{Na}$ amostra e período selecionados há programas de sete ou 10 minutos como o Comentários do Observador ou o Jogo limpo do Público, enquanto outros têm uma hora como no caso das entrevistas e debates à imagem do que acontece na rádio.

Quando analisamos o conteúdo dos podcasts verificamos que são, na esmagadora maioria (8), de informação e da editoria de Política (Gráfico 1). 


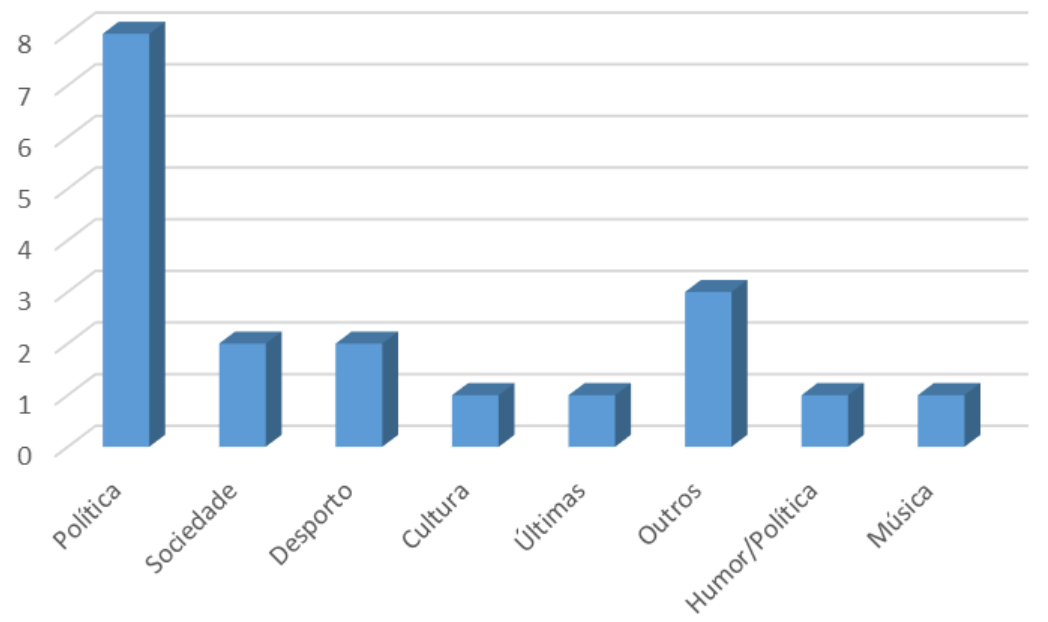

Gráfico 1: Tipo de conteúdo de Informação (por editorias) e Entretenimento (por área)

Não é um resultado surpreendente já que os jornais, ao contrário das rádios, não possuem uma área de entretenimento porque são produtos jornalísticos puros. A Política é uma das principais editorias dos sites dos jornais de referência (Lima \& Reis, 2013) e, como tal, é coerente que os podcasts espelhem as respetivas opções editoriais. De referir que alguns dos programas de Política abarcam a atualidade nacional e internacional e são, na sua esmagadora maioria de análise, comentário ou debate em que os protagonistas são, muitas vezes, jornalistas do próprio jornal que surgem com frequência nos painéis de programas opinativos de rádios e televisões. Ou seja, há uma rentabilização da "prata da casa" que foi ganhando alguma visibilidade noutros órgãos de comunicação social. De resto, o formato escolhido para estes programas é em tudo semelhante ao dos meios audiovisuais. E esta última consideração é igualmente válida para a editoria de Desporto.

No Desporto há dois programas, assim como na editoria Sociedade, e um na de Cultura. Na classificação de Últimas foi considerado o P24 por se tratar de um noticiário.

$\mathrm{Na}$ categoria Outros estão três programas: Reservado ao público do jornal Público, $F_{5}$ e A beleza das pequenas coisas do Expresso. Os dois primeiros são programas idênticos quanto à temática no sentido em que falam do próprio jornal embora com abordagens distintas. Não são autopromoções, embora apenas deem a visão interna sobre as temáticas escolhidas.

No tipo de conteúdo de Entretenimento foram encontrados exemplos de Informação e Entretenimento, tendo este último uma presença residual: dois em 19 podcasts.

Tendo como ponto de referência os géneros jornalísticos radiofónicos, regista-se o facto de a grande maioria dos podcasts ser opinativa e de não se ter encontrado exemplos dos novos géneros enunciados por Prata (2009) mais focados na interatividade e de Herreros (2008) mais ligados à componente sonora. Em dois dos três ciberjornais analisados não foram identificadas ferramentas interativas que permitam ao ciberouvinte registar ou enviar um feedback. Apenas o Público tem o endereço eletrónico do autor do programa e possui caixa de comentários. Em nenhum caso foram encontrados os 
exemplos idealizados por Herreros de ferramentas interativas que permitam qualquer registo sonoro por parte do ciberouvinte. Todos os programas permitem a partilha dos podcasts nas redes sociais.

Dos géneros jornalísticos foram excluídos o Ao vivo do Observador por ser de entretenimento e o Inimigo público do Público por não se enquadrar nos géneros jornalísticos. Ainda quanto aos géneros foram encontrados exemplos de informativos (4), opinativos (11) e de diálogo (2) (Gráfico 2).

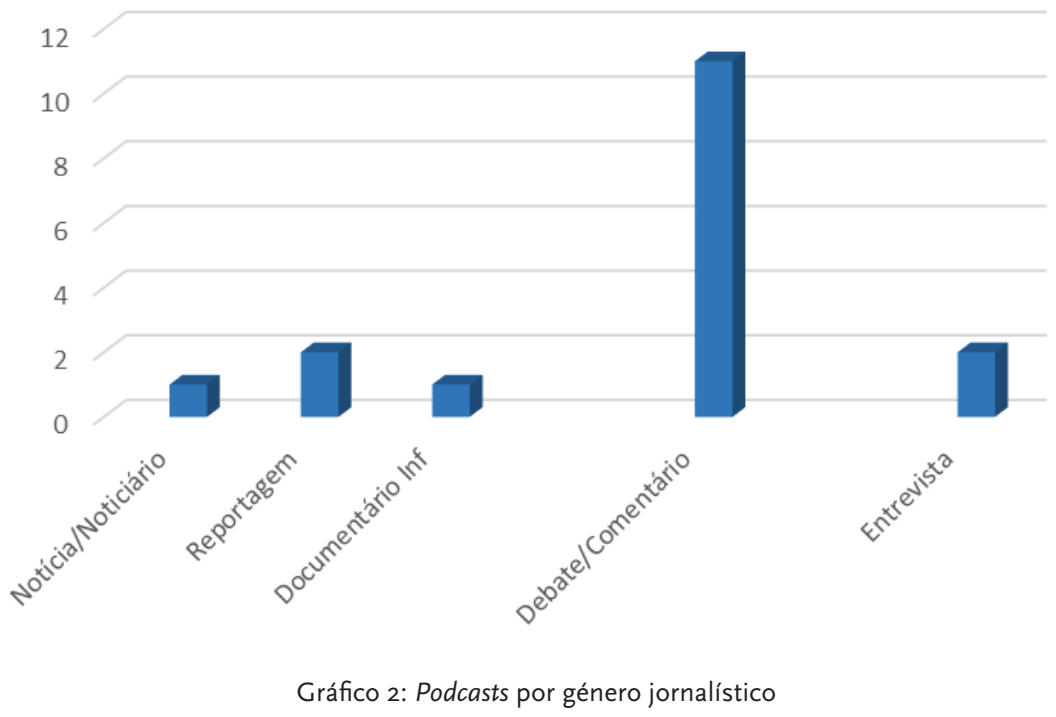

Da leitura do Gráfico 2 ressalta a preponderância da dupla categoria Debate/Comentário com 11 programas. A opção foi a de juntar estes dois géneros em face da constatação de que a maioria dos podcasts têm um caráter híbrido: são debates ou conversas entre comentadores. Apenas o Comentários do Observador se insere na categoria Comentário por se tratar efetivamente de um comentário puro feito a uma só voz.

Os géneros opinativos estão em clara maioria, mas há que referir que mesmo os programas categorizados como Debate/Comentário incluem outros recursos, como pequenas entrevistas ou reportagens ou declarações gravadas. Os comentadores são do próprio jornal ou convidados e alguns chamam ao debate especialistas que contribuem para uma visão mais factual ou de análise do tema em discussão. Como já foi referido, há um claro aproveitamento dos diretores, editores e jornalistas à imagem do que este segmento já faz nos meios audiovisuais. São caras e vozes conhecidas que os jornais potenciam nos seus próprios podcasts. É também através deles que os jornais se afirmam, além de veículos de informação, como opinion makers. Esta opção vai ao encontro daquilo que caracteriza o sistema mediático mediterrânico ou pluralista polarizado no qual Portugal se insere e em que o recurso ao comentário do especialista é recorrente e ocupa um lugar de relevo nos média (Hallin \& Mancini, 2010).

Dentro dos géneros informativos destaca-se o $F_{5}$ do Expresso, que corresponde às características do Documentário Informativo (Herreros, 1992). O F5 aborda um facto passado, contextualiza-o, recorda-o e recria-o com testemunhos da época e atuais - é 
uma reconstrução histórica, mesmo que recente no tempo, pelo que corresponde mais às características do Documentário Informativo (Herreros, 1992). Logo no primeiro (dos três únicos programas) a autora dá o mote: "Bem-vindos ao podcast $F_{5}$ : histórias cheias de gente, contadas pelas pessoas que as viveram e pelos repórteres que as contaram e não quiseram, ou não conseguiram, esquecê-las". Este género não é muito frequente na rádio e encontra nos jornais um terreno fértil pela memória histórica que os próprios jornais encerram nos seus arquivos, mas que ainda não tinha sido explorado desta forma. O F5 não se limita ao som, a página de cada episódio tem texto e imagens que no seu todo poderia ser considerado um trabalho multimédia do qual faz parte um podcast que se pode escutar isoladamente sem que seja prejudicado pela ausência do texto e da imagem. O áudio vale por si só, tem uma identidade própria independentemente do contexto ciberjornalístico em que se insere. É, talvez por isso, um dos exemplos mais prometedores no panorama dos podcast dos jornais portugueses, embora ainda se consiga estabelecer um paralelo com o produto radiofónico. Quanto aos restantes géneros foram classificados como Entrevista (2), Reportagem (2), e Notícia/Noticiário (1).

O podcast tem ainda como referencial a rádio e quando se aborda a vertente jornalística isso torna-se inevitável, mesmo que se encare o podcast como algo distinto da rádio. Essa questão já aqui foi abordada e torna-se pertinente quando se analisa a estrutura do produto sonoro que é o podcast, a sua linguagem, estética sonora e até a estrutura e escrita usadas na narrativa.

A estética sonora subjacente à rádio está presente nos áudios em podcast dos jornais e é utilizada da mesma forma. Quase todos possuem um indicador sonoro no início e fim do programa que é idêntico ao formato e função atribuídos ao genérico dos programas da rádio. Além do mais, tem uma estética idêntica: no arranque uma música sobre a qual o narrador apresenta o programa, autores e convidados, tema ou tópicos e, no final, a despedida. A exceção é o Observador, o que é natural se tivermos em conta a natureza dos programas que são produzidos para serem vistos e ouvidos, ou seja, vídeos, alguns com elementos gráficos ou legendas. A quem ouve falta uma parcela da informação que o oriente na escuta. O exemplo mais flagrante é o B.I.C.A. que começa a meio de uma conversa e acaba da mesma forma, sem que auditivamente fossem identificados os intervenientes. A ideia será a de captar apenas um momento de uma conversa que já começou e que se prolonga além do registo gravado, mas a verdade é que falta informação para situar o ciberouvinte que apenas tem acesso à versão áudio, sem o suporte escrito no site ou o vídeo.

Além da temporalidade, as maiores diferenças entre a rádio e estes programas em podcast registam-se na estrutura do texto, linguagem e escrita. A linguagem radiofónica de Balsebre está ausente da grande maioria dos podcasts, o que se explica também pela predominância dos géneros opinativos. Os podcasts de reportagem, por exemplo, fazem uso de forma contida de todos os elementos enunciados por Balsebre (1994): palavra, música, efeitos ou ruídos, silêncio.

É na estrutura e na escrita das narrativas que se revelam as maiores diferenças entre os podcasts e a rádio. Regra geral identifica-se a pirâmide invertida na hierarquização das 
informações, contudo a técnica de espiral típica dos textos para rádio está completamente ausente. Ou é uma opção deliberada ou assenta na convicção de que podemos reouvir o que acabamos de ouvir "puxando a fita" para trás, o que não é possível na rádio em fluxo contínuo. Escrever para ser dito e ouvido é uma das regras básicas da rádio e que não encontra paralelo na maioria dos textos ouvidos nos podcasts dos jornais. São frequentes as frases longas, construções frásicas elaboradas, frases intercalares que correspondem a várias ideias numa única frase, vocabulário complexo, palavras de difícil pronunciação. Tudo isto dificulta a leitura dos textos e, por consequência, perceção da mensagem por parte do ouvinte sob o risco de se perder no sentido da frase ou no conteúdo. Mesmo assumindo que os podcasts dos jornais não são rádio, escrever para ser ouvido terá sempre de obedecer às particularidades da audição o que nem sempre é tido em conta. Isto é "mais audível" sobretudo no $P_{24}$ porque são notícias cuja autopromoção enfatiza o facto de serem notícias para serem ouvidas.

O $P_{24}$ é, de resto, um caso que não encontra paralelo nos média nacionais, nem mesmo nas rádios. Cabe-nos referir a história do seu lançamento e antecedentes já que se trata de um formato inovador no panorama do ciberjornalismo português. Em março de 2017, o jornal Público anunciou o lançamento de um noticiário em áudio personalizado. As notícias em áudio são "selecionadas a partir dos interesses de cada pessoa" ao que se juntam algumas escolhas do editor. "O objetivo do Público foi criar um sistema que não fechasse os utilizadores dentro daquilo a que frequentemente se chama as suas bolhas de interesses". Surge assim um noticiário áudio. Não se trata de um serviço inédito. O mesmo jornal já tinha integrado, na viragem do século, um projeto idêntico com a Rádio Nova do Porto para a operadora Optimus (todos propriedade do grupo Sonae) na elaboração de um noticiário áudio escutado pelo cliente da Optimus e que era acedido através de um número de telefone criado para o efeito.

O P24 teve a primeira edição em 26 de abril de 2017. A duração do noticiário ronda os 9 a 10 minutos. Na apresentação escrita são distinguidas as funções de edição e locução. O editor não tem a mesma função do editor de noticiário da rádio presente desde o início até ao fim fazendo a ligação entre as notícias. No P24 cada notícia pode ter uma voz diferente. As notícias têm uma duração média entre os 20 e os 50 segundos, o que corresponde à duração média de uma notícia "seca" em rádio, ou seja, sem sons.

Relativamente ao conteúdo, o P24 insere-se na Informação, nos géneros jornalísticos informativos e poderia ter cabimento simultâneo nas categorias de Notícia e Noticiário. No entanto, não obedece ao conceito radiofónico deste último porque são notícias isoladas, sujeitas a um alinhamento variável de utilizador para utilizador.

A notícia não obedece nem à estrutura (primeira frase curta, pirâmide invertida e técnica de espiral) nem às regras de escrita radiofónicas (orientadas para a notícia ser dita e ouvida). Por vezes, há notícias com sons, aquilo a que na gíria de uma redação de rádio se chama RM, normalmente vozes dos protagonistas. Aquilo que mais o aproxima do género noticiário, em termos de estética sonora, é ter uma cortina, ou seja, um indicador sonoro, no início, entre as notícias e no final. O $P_{24}$ pode não ser considerado um noticiário se tivermos como referencial a rádio, mas corresponde ao conceito que o 
leitor/ouvinte tem e espera desse tipo de conteúdo. Tanto assim é que a opção foi batizar o produto de Noticiário.

O P24 vai ao encontro daquilo que João Paulo Meneses em 2008 antecipou para a rádio em 2018 e a que chamou "a desconstrução 'ao milímetro' por oferta": poderá haver um podcast por noticiário, mas sobretudo um podcast por notícia" através da subscrição de tags (Meneses, 2012). A visão de Meneses, afinal, concretizou-se não na rádio, mas num jornal.

Uma nota, relevante, para o facto de o noticiário no iTunes e no Soundcloud ter um spot de publicidade, isolado por cortinas sonoras antes da primeira notícia, o que não acontece nem no site nem na aplicação mobile. É o único podcast, do Público e dos restantes jornais portugueses, que tem publicidade associada, o que indicia um claro desperdício no aproveitamento do potencial do podcast enquanto fonte de receitas.

\section{CONSIDERAÇÕES FINAIS}

O objetivo deste estudo foi o de caracterizar o áudio em podcast dos sites dos jornais ou revistas de informação geral portugueses. O que se pretende é perceber como um jornal em ambiente digital desenvolve produtos sonoros e se estes contêm elementos distintivos que possam revelar uma identidade própria. A primeira conclusão é a de que os ciberjornais portugueses ainda não apostam nos produtos sonoros e no podcast. Em 10 publicações apenas três têm podcast e destas uma usa o podcast de forma meramente instrumental.

A segunda conclusão é a de que os áudios em podcast têm uma presença discreta nas homepages dos jornais que remetem para a secundarização do som no universo dos conteúdos dos ciberjornais portugueses. Embora seja de registar um significativo avanço nos últimos anos os produtos sonoros ainda não são tão valorizados como outros recursos multimédia nomeadamente o vídeo ou a fotografia. Ou seja, o áudio é um produto duplamente invisível: não se ouve nem se vê nos sites dos jornais.

Há outras conclusões a reter tendo como referência a rádio. A temporalidade e a periodicidade são as duas características que mais afastam os podcasts dos jornais dos das rádios, porque não têm uma duração fixa nem uma periodicidade certa. Os jornais não estão sujeitos ao rigor de uma grelha de programação pela qual se rege a rádio determinada por períodos fixos de emissão em que os programas cumprem uma duração e uma hora de emissão inflexíveis, o que se reflete também na duração e data e hora de publicação dos podcasts das rádios. Não há um fluxo contínuo pré-determinado nem uma emissão e consumo em tempo real, como na rádio.

No exemplo português, das quatro funções identificadas por Correyero Ruiz e Baladrón Pazos (2007) duas verificam-se parcialmente e duas estão ainda por se concretizar. No geral, os podcasts dos três jornais destacam as notícias do dia, mas não são usados para dar os destaques ou exclusivos do jornal que habitualmente são difundidos pelas newsletters e nas redes sociais de cada publicação. Os podcasts são, efetivamente, um meio de difusão de entrevistas, debates e comentários que o próprio jornal produz. $\mathrm{E}$ 
são novos produtos, diferentes do meio-mãe, o que implica o uso de recursos humanos e técnicos diferentes dos que até aqui eram usados. Das funções de Correyero Ruiz e Baladrón Pazos (2007), a última não se verifica no caso português, a que coloca o podcast como uma ferramenta para estimular a participação dos leitores. A possibilidade de criar uma aproximação maior e diferente com os leitores não passa pela interação porque há uma ausência generalizada de ferramentas interativas ou de participação.

Às funções aqui enunciadas pode acrescentar-se uma nova que resulta dos géneros mais utilizados pelos jornais, os opinativos. Os jornais usam o podcast como uma estratégia de valorização e afirmação do jornal enquanto opinion maker. Desta forma consolidam uma tendência dos últimos anos em que os jornalistas seniores, diretores e editores integram os painéis de comentadores e analistas das rádios e televisões.

A relação entre podcast e jornais contribui para a adaptação a uma nova realidade, os jornais já não estão fechados no seu velho nicho tradicional, abrem-se a outras linguagens e experimentam-nas com a vantagem de não estarem "espartilhados" pelas regras que regem os conteúdos da rádio. Pode dizer-se que esta é uma vantagem ainda não explorada. Os podcasts dos jornais encontram paralelo nos produtos radiofónicos, têm um conceito e uma estrutura idênticos aos programas de entretenimento ou de informação das rádios. Aliás, não foram encontrados exemplos novos ou inovadores que nos permitissem afirmar que os atuais podcasts dos jornais portugueses são diferentes dos das rádios, ou seja, dos programas retirados das suas emissões. De resto, pode mesmo afirmar-se que os podcasts dos jornais portugueses são feitos à imagem dos programas de rádio, a que não será alheio o facto de alguns dos autores, não todos, terem alguma experiência no meio rádio. Os programas possuem uma estrutura idêntica, têm uma noção radiofónica da estética e do uso dos códigos sonoros na narrativa e encaixam-se facilmente nos géneros radiofónicos. No geral, ouvi-los é, no fundo, ouvir um programa de rádio. Isto mesmo que haja diferenças, que existem, nomeadamente ao nível da linguagem e regras de escrita do jornalismo radiofónico. Mesmo assim, não significa que a mensagem não alcance o seu objetivo, uma vez que, tratando-se de um conteúdo online, tem quase sempre um suporte escrito, um lead, com um resumo dos conteúdos sonoros.

Para os jornais o podcast representa um esforço na diversificação de recursos e de conteúdos que pode conquistar novos públicos. E aqui, os jornais podem seguir a tendência da rádio nos últimos anos na sedução e consolidação de pequenos nichos com interesses muito específicos que, ao mesmo tempo, podem angariar novos mercados na publicidade. O caminho pode ser então o da fidelização na assinatura dos conteúdos sonoros em podcast.

Se o podcast é uma possibilidade até aqui subaproveitada pelos jornais, ela contribui para a diversidade e consequente enriquecimento dos seus conteúdos que thes podem trazer outro tipo de públicos e publicidade. Contudo, o podcast não é ainda entendido como um gerador de receitas. No geral, os podcasts não têm publicidade associada. Um claro desperdício de uma fonte de receita que pode ser uma forma de financiar os produtos áudio que requerem recursos humanos e técnicos especializados. 
Perante as possibilidades do aproveitamento do áudio e do podcast a conclusão que sobressai deste estudo é que depois de um momento de tímido investimento nos conteúdos áudio e de avanços e recuos, os jornais portugueses começaram, finalmente, a apostar no som, seguindo a tendência dos jornais europeus. Apesar de ser evidente a influência da rádio nos produtos sonoros em podcasts dos jornais portugueses, ainda se está numa fase de experimentação e exploração quer ao nível dos formatos quer ao nível dos conteúdos.

Em face da realidade portuguesa, a teoria de Bonini apenas se aplica em parte, ao nível dos formatos e conteúdos, mas não ao nível do modelo de negócio e da rentabilização do produto sonoro. Portugal está, assim, com um pé na segunda fase do podcast. O futuro dirá se os conteúdos sonoros em podcast nos ciberjornais estão a caminho de uma identidade própria e distinta da rádio.

\section{REFERÊNCIAS BIBLIOGRÁFICAS}

Balsebre, A. (1994). El lenguaje radiofónico. Madrid: Catedra.

Bastos, H. (2006). Ciberjornalismo: dos primórdios ao impasse. Comunicação e Sociedade, 9, 103-112. doi: $10.17231 /$ comsoc.9(2006).1158

Bastos, H. (2015). Origens e evolução do ciberjornalismo em Portugal, os primeiros 20 anos (1995-2015). Porto: Edições Afrontamento.

Berry, R. (2006). Will the iPod kill the radio star? In A. Crisell, Radio, critical concepts in Media and Cultural Studies - vol III (pp. 143-162). UK: Routledge

Berry, R. (2016). Podcasting: considering the evolution of the medium and its association with the word "radio". The Radio Journal International Studies in Broadcast and Audio Media, 14(1), 7-22. doi: 10.1386/ rjao.14.1.7_1

Bonini, T. (2015). The "second age" of podcasting: reframing podcasting as a new digital mass medium. Quaderns del cac, 41 XVIII, 23-33.

Correyero Ruiz, B. \& Baladrón Pazos, A. (2007). El Podcasting en los medios de comunicación españoles. In J. Lassa \& F. Turmo (Eds.), Presente y futuro de la comunicación digital (pp. 154-169). Zaragoça: Asociación de Prensa de Aragón. Retirado de http://www.labcom-ifp.ubi.pt/publicacoes/201501131553libro_electronico.pdf

Digital news fact sheet. (2017, 7 de agosto). Pew Research Centre. Retirado de http://www.journalism.org/ fact-sheet/digital-news/

Gallego, I. (2010). Podcasting. Nuevos modelos de distribución para contenidos sonoros. Barcelona: Editorial UOC.

Garrand, T. (2006). Writing for multimedia and the web. Massachusets: Focal Press.

Hallin, D. \& Mancini, P. (2010). Sistemas de media: estudo comparativo. Lisboa: Livros Horizonte.

Herreros, C. (1992). Generos informativos audiovisuales. Madrid: Editorial Ciencia.

Herreros, C. (2008). La radio en internet. Buenos Aires: La Cruija. 
Lima, H. \& Reis, A. (2013). A hierarquização de notícias e os comentários do público nos sites de quatro diários portugueses. In M. L. Martins \& J. Veríssimo (Eds.), Comunicação global, cultura e tecnologia. Livro de Atas do $8^{\circ}$ SOPCOM (pp. 669-674). Lisboa: Sopcom. Retirado de https://www.dropbox.com/s/ bgcaeqryntrxpo8/livro_de_Latas_80_SOPCOM.pdf?dl=0

Martínez-Costa, M. \& Unzueta, J. (2005). Lenguaje, géneros y programas de radio. Pamplona: EUNSA.

Meneses, J. P. (2012). Estudos sobre a rádio, passado, presente, futuro. Porto: Legis Editora.

Podcasting: fact sheet. (2016, 15 de junho). Pew Research Centre. Retirado de http://www.journalism. org/2016/06/15/podcasting-fact-sheet;/

Prado, E. (1985). Estrutura da informação radiofónica. São Paulo: Summus Editorial.

Prata, N. (2009). WEBradio. Florianopolis: Editora Insular.

P24: Público lança noticiário personalizado em áudio (2017, 24 de abril). Público. Retirado de https://www. publico.pt/2017/04/24/tecnologia/noticia/publico-lanca-noticiario-personalizado-em-audio-1769913

Saímos do Netscope. E mostramos os nossos números. (2016, 13 de abril). Observador. Retirado de http:// observador.pt/2016/04/13/saimos-do-netscope-mostramos-os-numeros/

Zamith, F. (2008). Ciberjornalismo: as potencialidades da internet nos sites noticiosos portugueses. Porto: Edições Afrontamento.

Zamith, F. (2017). Cibermeios portugueses: 10 anos de lenta evolução. In A. I. Reis, F. Zamith, H. Bastos \& P. Jerónimo (Eds.), Liuro de Atas V Congresso Internacional de Ciberjornalismo (pp. 26-37). Porto: Universidade do Porto. Retirado de https://repositorio-aberto.up.pt/bitstream/10216/104040/2/190201. pdf

\section{NOTA BIOGRÁFICA}

Ana Isabel Reis é Professora Auxiliar da Faculdade de Letras da Universidade do Porto. É doutorada em Ciências da Comunicação - Estudos de Jornalismo pela Universidade do Minho e professora de rádio e jornalismo na Universidade do Porto. Tem desenvolvido trabalhos de investigação sobre o jornalismo radiofónico e o som na internet, história da rádio e também sobre experiências laboratoriais em plataformas digitais no ensino do jornalismo.

E-mail: aisabelreis@gmail.com

Morada: Faculdade de Letras - Universidade do Porto, Via Panorâmica, s/n, 4150564 Porto (Portugal)

\section{* Submetido: 30-11-2017 \\ *Aceite: 15-02-2018}

